\title{
Analysis of 5-Hydroxymethyl-2-Furfuraldehyde in Electrolytic Products and Energy Drink Products
}

\author{
Pornpimol Muangthai ${ }^{1}$, Yonrawee Wiwatchankit ${ }^{1}$, \\ ${ }^{I}$ Department of Chemistry, Faculty of Science, Srinakharinwirot University,Bangkok, Thailand
}

\begin{abstract}
Electrolytic products and energy drink products are used as electrolyte to heal diarrehoea, energy serving for athlete and labour people.Both products contain the main component such as sodium ion, potassium ion, sugar, artificial flavor and colour. 5-Hydroxymethyl-2-furfuraldehyde(HMF) is the one product from browning reaction in food. It was claimed as a toxic substance. The aim of this work was to analyse HMF content in electrolytic products and energy drink products by High Performance Liquid Chromatography. The optimum conditions for analysis HMF were studied and validated method, then applied for analysis HMF content in products. The optimization method showed that HMF could be eluted with isocratic elution by the mixture of water/acetonitrile $(90: 10, \mathrm{v} / \mathrm{v})$ that controlled flow rate at $1.5 \mathrm{ml} / \mathrm{min}$. and detected at $280 \mathrm{~nm}$ by diode array detector (DAD). The limit of detection (LOD) and limit of quantitation $(L O Q)$ were $0.89 \mu \mathrm{g} / \mathrm{L}$ and $2.9 \mu \mathrm{g} / \mathrm{L}$, respectively. The relative standard deviation $(\% R S D$ ) (replicate numbers $=10$ ) was $0.55 \%$.The HMF could be detected in both samples products within the range of 0.03- $6 \mathrm{mg} / \mathrm{L}$.This work proved that the toxic substance such as hydroxymethylfurfuraldehyde present in the electrolytic products and energy drink products, so the consumer should care about the using of electrolytic products.
\end{abstract}

Keywords: 5-Hydroxymethyl-2-Furfuraldehyde,HMF , Electrolytic Products, Energy Drink Products

\section{Introduction}

Electrolyte products are the healthy products used for medical purpose such as the deficiency of electrolyte in human body.An important electrolyte products as saline or normal saline frequently used for patients who cannot take fluids orally by intravenous drips[1]. Normal saline is also used for aseptic purpose , used for nasal washes to relieve the symptoms of the cold too[2]. Other saline products as ophthalmic eye drops are the saline - containing drops used as an ocular route to administer that may contained steroids, antihistamines, sympathomimetics, non-steroidal anti-inflammatory drugs or topical anesthetics [2]. Hypertonic saline are mucoactive agent used to dissolve the mucous in throat or internal tract of nose. However, some of the electrolyte products are formulated for sold as powder oral rehydration salts form. This product is very popular for diarrehoea people to heal the electrolytic balance in body. All above referred electrolyte products are the electrolyte in the form of saline and oral rehydration electrolyte, which contain sodium chloride in the range of $0.22-7 \%$ and dextrose or glucose in the range of $4-5 \%[3]$.

Energy drink products is now the one popular products among the youth people[4,5].The strategies to sale the energy drink also state that the energy drink products perform energy for athletic performance[6]. The youth people consume energy drinks products prior to or during exercise and sporting events to boost their physical performance[7,8]. Now,energy drink products is produced by mixing with many substance such as food color, food flavour, high sugar content and caffeine[9]. There have many reports inform some toxic from drinking the energy drink products such as cardiac dysrhythmias, dilated cardiomyopathy, rhabdomyolysis,kidney failure and sudden death[10,11]. However, there has no report about the content of the browning substance as 5-Hydroxymethyl-2- furfuraldehyde.

5-Hydroxymethyl-2- furfuraldehyde(HMF) is an important products from nonenzymatic browning reaction and forms by the reaction between carbonyl group in sugar and amino group in amino acid of protein which is known as Maillard browning reaction.[12,13]. It has a formular structure as showed in fig. 1.

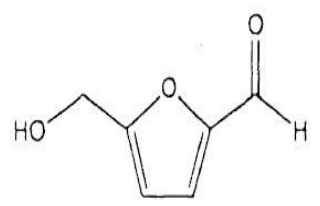

Figure1.Structural formula of 5-Hydroxymethyl- 2-furfuraldehyde 
However , HMF is also the intermediate products in the condensation of sugar between heating which is known as caramellization reaction.[14,15]. HMF is also formed between storaging the products. HMF is a toxic substance that was claimed to be carcinogenic substance $[16,17]$ and effect on DNA[18] too.

Nowaday,HMF is an importance index to indicate the quality of honey $[19,20]$ and fruit juice samples $[21,22,23]$. There have many reports that referred the analysis of HMF in many foods such as beer[24],cereals[25,26],bakery products[27], coffee [28], dried fruits[29] and milk products[30]. From the above details, the browning product as HMF may presented in the normal saline solution, electrolyte solution, powder electrolyte and energy drink products after storage before sold to consumer. Since, the glucose is also be the one component in electrolyte products and energy drink products especially in solid electrolyte powder products and energy drink products, so that HMF may be formed by the Maillard reaction or caramellization reaction. There have no report about the study of HMF content in all electrolyte products. The aim of this work was to determine the HMF content in electrolytic products and energy drink products by reverse phase high performance liquid chromatography. The method for analysis HMF in sample was optimised and validated by analysis the LOD, LOQ and RSD.Then, the optimum method was applied to analyse the HMF content in the electrolyte products such as oral rehydration salts, normal saline products and energy drink products were analysed the HMF content.

\subsection{Materials}

\section{Materials And Method}

\subsubsection{Chemicals}

5-Hydroxymethyl-2-furfuraldehyde standard Chromatographic grade was purchased from Fluka. Potassium ferrocyanide trihydrate $\left(\mathrm{K}_{4} \mathrm{Fe}(\mathrm{CN})_{6} \cdot 3 \mathrm{H}_{2} \mathrm{O}\right)$ and $\mathrm{Zinc}$ acetate dehydrate $\left(\mathrm{Zn}\left(\mathrm{OOCH}_{3}\right)_{6} .2 \mathrm{H}_{2} \mathrm{O}\right)$ were of analytical reagent grade from Merck. Acetonitrile (HPLC grade), ethanol (AR grade), methanol (HPLC grade) were purchased from Sigma aldrich.

\subsubsection{Samples}

The electrolyte products 20 samples such as normal saline liquid samples, electrolyte solid powder samples with lemon flavor, with orange flavour, nasal saline products, optical saline products were purchased from the drug store in Bangkok, Thailand. The energy drink products 16 samples such as lipovitan D, Red Carabao, Red Bull, Gaterate were purchased from the supermarket in Bangkok,Thailand.

\subsection{Experimental method}

2.2.1 Study on the optimum condition for analysis of HMF ( modified from [25]) The 5-Hydroxymethyl-2furfuraldehyde standard solution was prepared to $1000 \mathrm{ppm}$ as stocking standard solution and then prepared to be calibration standard solution as $0.01-10 \mathrm{ppm}$. Those calibration standard solutions were injected to high performance liquid chromatography (Agilent, HP1100) , passed through the C18 guard cartridge which coupled with the reverse phase C18 column(VertiSepTM pHendure ) $5 \mu \mathrm{m}, 4.6 \times 250 \mathrm{~mm}$ and eluted with the mobile phase solution of water : acetonitrile by variation the ratios as 97:3, 95:5, 90:10 and 80:20, controlled flow rate at $1.5 \mathrm{ml} / \mathrm{min}$. Then the signal peak was detected by diode array detector at $280 \mathrm{~nm}$. The chromatogram was recorded and plotted the area of the standard HMF peak VS the standard concentration to be the standard calibration curve.

2.2.2 Validation method The standard HMF solution $0.001 \mathrm{ppm}$ was injected to $\mathrm{C} 18$ column and operated the condition as in the part 2.1 by the optimum method ratio of water : acetonitrile. The standard HMF was injected ten replications and recorded the area of standard HMF peak for calculation of LOD and LOQ as the following equation1) and 2) respectively[32].

$$
\begin{aligned}
& \mathrm{LOD}=3 \mathrm{SD} / \text { slope } \quad \ldots \ldots .1) \\
& \mathrm{LOQ}=10 \mathrm{SD} / \text { slope } \quad \ldots \ldots . .2)
\end{aligned}
$$

\subsubsection{Analysis of HMF in electrolytic products.}

The samples were pipetted $5.00 \mathrm{ml}$, mixed with $1 \mathrm{ml}$ of Carrez I solution, $1 \mathrm{ml}$ of Carrez II solution ( modified from [31] and diluted to $50 \mathrm{ml}$ with deionised water.Then the sample mixed solutions were filtered through cellulose acetate membrane syringe filter $(0.45$ micron) before injected through the $\mathrm{C} 18$ column of HPLC instrumentation and eluted with the mobile phase solution as in part 2.1.The area of HMF peak was recorded and compared with the standard calibration curve of standard HMF solution.

Note: Carrez I is $15 \% \mathrm{w} / \mathrm{v}$ of the $\mathrm{K}_{4} \mathrm{Fe}(\mathrm{CN})_{6} .3 \mathrm{H}_{2} \mathrm{O}$ standard solution.

CarrezII is $15 \% \mathrm{w} / \mathrm{v}$ of the $\mathrm{Zn}\left(\mathrm{OOCH}_{3}\right)_{6} 2_{2} \mathrm{H}_{2} \mathrm{O}$ standard solution. 


\section{Results And Discussion}

The results from part 2.1 were revealed that the standard HMF chromatogram from each system of mobile phase solvent showed the different retention time as in table 1.

Table 1: The retention time of standard HMF in each mobile phase system.

\begin{tabular}{ccc}
\hline $\begin{array}{c}\text { Condition } \\
\text { number }\end{array}$ & $\begin{array}{c}\text { Ratio } \\
\text { Water : Acetonitrile }\end{array}$ & $\begin{array}{c}\text { retention time } \\
(\text { min) }\end{array}$ \\
\hline 1 & $97: 3$ & $9.3 \pm 0.010$ \\
2 & $95: 5$ & $6.6 \pm 0.010$ \\
3 & $90: 10$ & $4.0 \pm 0.010$ \\
4 & $80: 20$ & $2.6 \pm 0.010$ \\
\hline
\end{tabular}

The retention time of standard HMF peak depended on the ratio of mobile phase component. The increasing of acetonitrile content reduced the time of HMF that retained in the column. Since HMF formular structure from figurel shows that it is the polar substance, so the polar strength of mobile effect on the retention time for elution HMF that retained in the nonpolar phase column as reffered by [5]. The standard HMF chromatogram of condition 3 was shown as in fig. 2

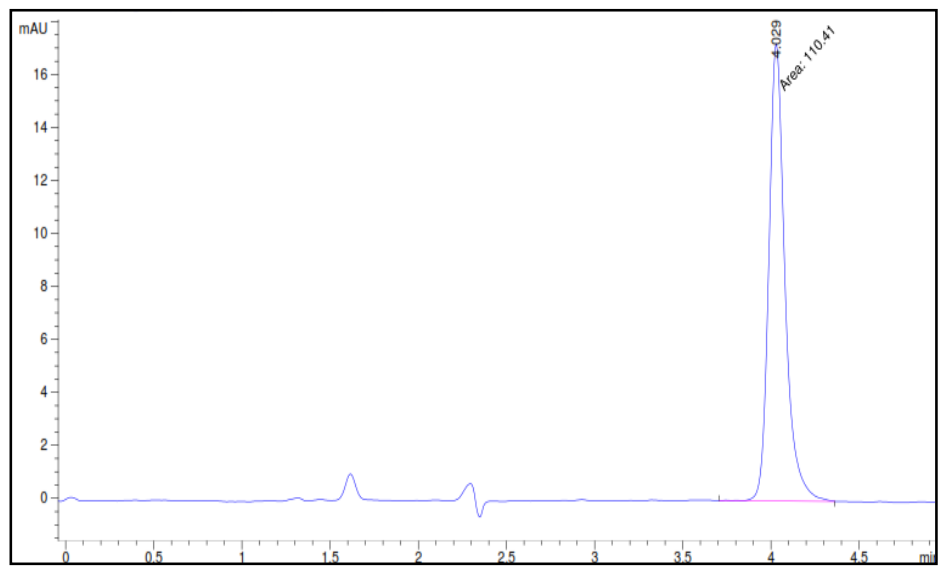

Figure 2. The standard HMF chromatogram

The retention time of standard HMF solution which used the condition 3 showed at 4.0 minutes on the chromatogram. The condition 3 that contained water : acetonitrile was chosen to be the best system in this experiment, since the retention time of HMF was completely separated from the interference in sample.

The condition 3 was applied in the analysis of standard HMF which was spiked in the electrolyte sample as showed in fig. 3.

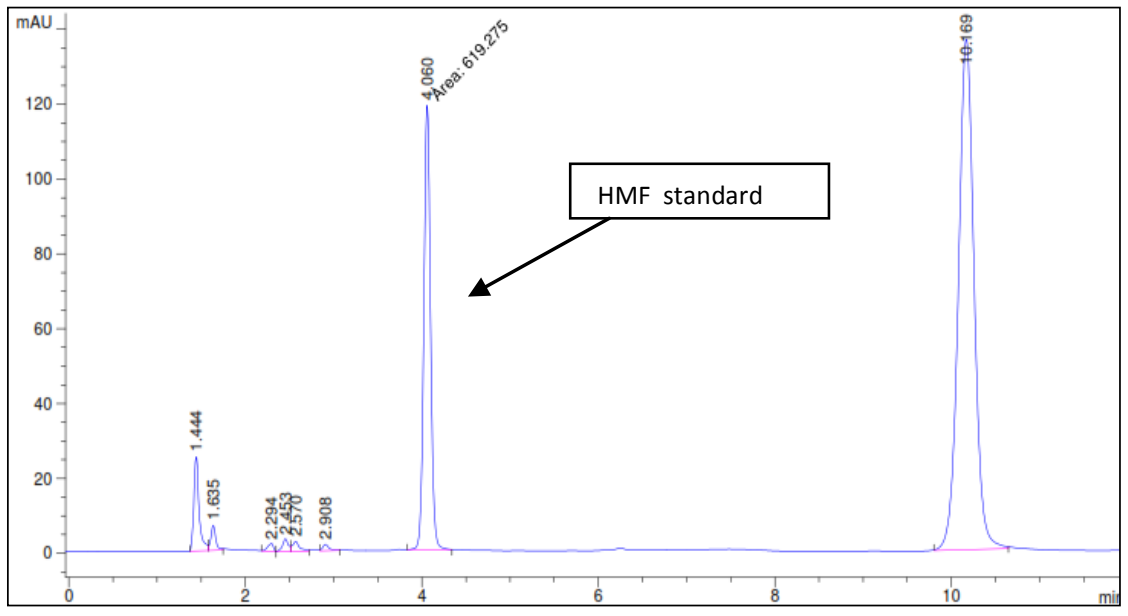

Figure 3. The chromatogram of standard HMF which was spiked in electrolyte sample products. 
From fig. 3, the HMF peak showed after the interference substance in electrolyte products and completely separated from all substances. In this work, we concluded that the condition 3 was the best or optimum condition in the HMF analysis of the work.

Thus, the condition 3 method was validated to evaluate the efficiency of method as in part 2.2.2. The limit of detection (LOD) and limit of quantitation (LOQ) were $0.89 \mu \mathrm{g} / \mathrm{L}$ and $2.9 \mu \mathrm{g} / \mathrm{L}$, respectively. The relative standard deviation $(\% \mathrm{RSD}$ ) ( replicate numbers for this experiment $=10$ ) was $0.55 \%$.

The electrolyte products were divided into 2 groups, the one was saline and oral dehydration powder products. The HMF could be detected in each products as presented in fig. 4.and fig.5.

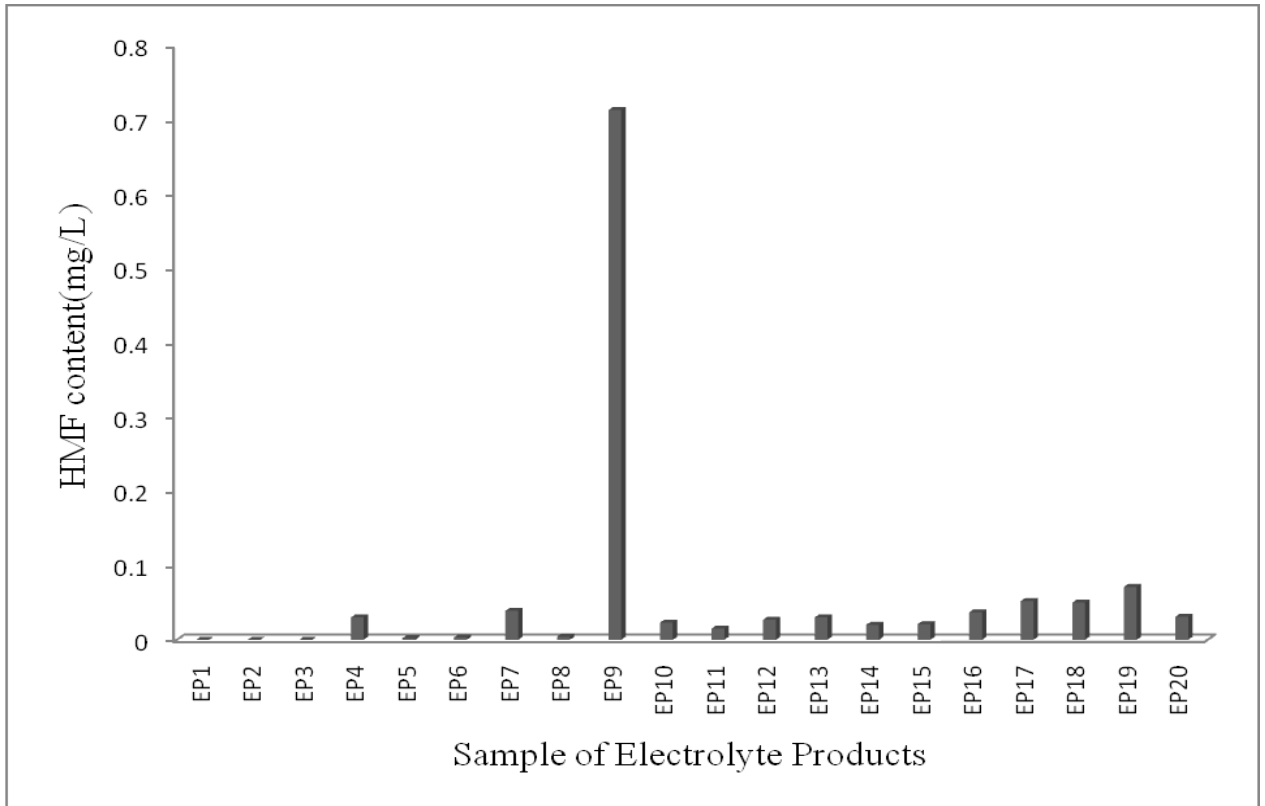

Figure 4 HMF content in normal saline liquid sample and oral dehydration powder products

Note: $\mathrm{EP}=$ electrolyte saline sample and oral dehydration powder products

Number $1-8=$ normal saline samples

Number $9-20=$ oral dehydration powder products

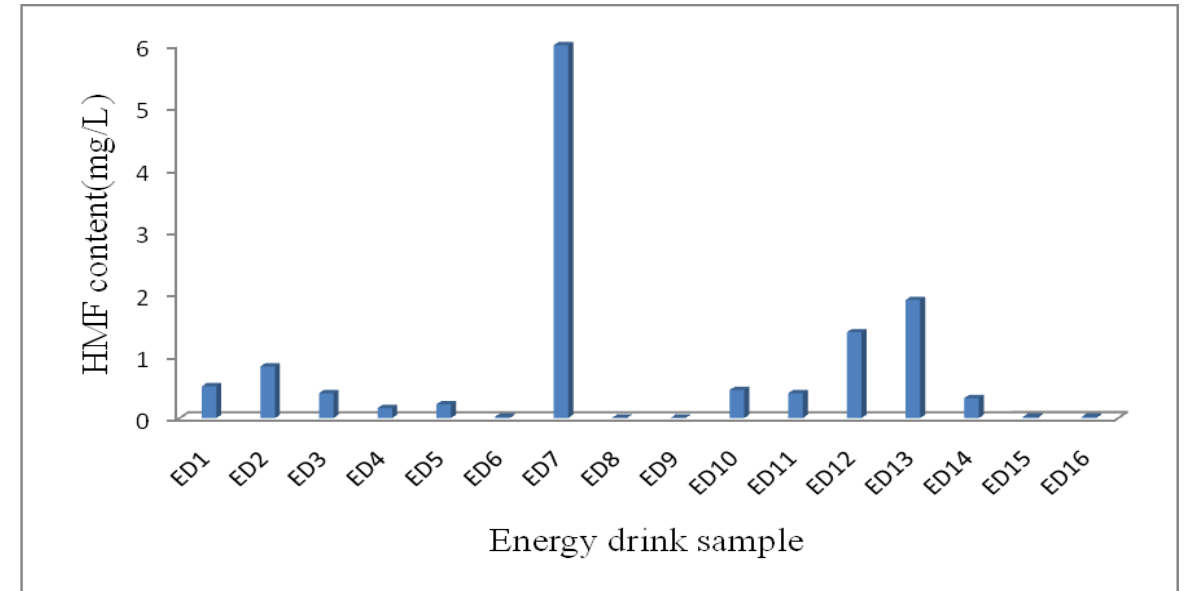

Figure 5 HMF content in energy drink samples

Note: $\quad$ ED $=$ energy drink sample

Number 1-16= energy drink sample number $1-16$

From figure 5 , the HMF content in energy drink products could be analysed and presented approximately in the range of $0.03-6.0 \mathrm{mg} / \mathrm{L}$ which higher than the HMF content that found in saline and dehydrated powder sample as in figure 4. The sample ED 9 which was the energy drink in brand of Gaterade (Lemon flavor) contained the highest HMF content about $6 \mathrm{mg} / \mathrm{L}$. The energy drink samples contained many 
substances such as sugar, some amino acid, caffeine, flavor additive , food color additive, so those samples have more chance to form browning substance as HMF by caramellization and Maillard reaction as referred by Hodge, J. E. The HMF content in normal saline samples ( EP 1-3,5-6) were too low and could not be detected by this method.It was noticed that the HMF content was found higher level in oral dehydrated powder products with added artificial flavor substance than the normal oral dehydrated powder products. It may be the effect of other additive compound in sample that could form browning substance.

These results confirmed that the browning substance such as HMF could occurred in electrolytic products, energy drink or sport drink, normal saline and oral dehydrated powder products. The HMF content found in all electrolytic products still too low. Now, there was no any regulation to control this toxic substance in the electrolytic products and energy drink products. However, the storage effect of each products for a long time may activate the occurrence of HMF as referred by [5].

\section{Conclusion}

This work presented that the optimum method to analyse the browning substance as Hydroxymethylfurfuraldehyde by reverse phase high performance liquid chromatography was to use C18 column as stationary phase and eluted the system with water : acetonitrile (90:10) as mobile phase solvent by isocratic gradient elution method and controlled flow rate at $1.5 \mathrm{ml} / \mathrm{min}$. The detection of HMF was measured at $280 \mathrm{~nm}$ by diode array detector. The HMF showed its peak approximately at 4.0 min of $\mathrm{R}_{\mathrm{T}}$. From the validation method showed that LOD and LOQ of this analysis method was $0.89 \mu \mathrm{g} / \mathrm{L}$ and $2.9 \mu \mathrm{g} / \mathrm{L}$, respectively.The relative standard deviation(\%RSD) ( replicate numbers $=10$ ) was $0.55 \%$. The optimized method showed the good value of limit of detection in the level of microgram $/ \mathrm{L}$, this mean that this applied method was the sensitive method which sensitive to detect the toxic substance in normal saline products.

After application of this method to analyse the HMF in 36 electrolytic products that divided into 2 groups, it showed that the energy drink or sport drink products contained the higher HMF content more than the other group.The HMF found in all samples were approximately in the range of $0.03-6.0 \mathrm{mg} / \mathrm{L}$. The found HMF content was still too low, but the people should not be use the electrolytic products after storage for a long time since HMF could be form during storage as refered by [33].

\section{Acknowledgements}

The author wish to thank the research field of Faculty of Science, Srinakharinwirot University to support the funding from the research section income in the annual of 2013.

\section{References}

[1]. GF Strandvik. Hypertonic saline in critical care: a review of the literature and guidelines for use in hypotensive states and raised intracranial pressure. Anaesthesia .64 (9): ,2009, 990-1003.

[2]. Awad, Sherif; P Allison Simon, N Lobo Dileep N. The history of $0.9 \%$ saline. Clinical nutrition (Edinburgh, Scotland) 27 (2),2008,179-188.

[3]. SM Seifert,JL Schaechter,ER Hershorin,SE Lipshultz. Health effects of energy drinks on children, adolescents, and young adults. Pediatrics ,127: 2011.511-528.

[4]. MA Howard and CA Marczinski, Acute effects of a glucose energy drink on behavioral control. Journal of Experimental and Clinical Psychopharmacology. 18(6),2010, 553-61.

[5]. WH Oddy, TA O'Sullivan, Energy drinks for children and adolescents: Erring on the side of caution may reduce long term health risks. Brit Med J ,2010,340:64.

[6]. M Rath, Energy drinks: what is all the type? The dangers of energy drink consumption. J Am Acad Nurse Pract ,24:2012,70-76.

[7]. K Clauson, K Shields, C McQueen,N Persad, Safety issues associated with commercially available energy drinks. J Am Pharm Assoc ,48,2008,55-67.

[8]. SL Ballard, JJ Wellborn-Kim, KA Clauson . Effects of commercial energy drink consumption on athletic performance and body composition. Phys Sports med,38, 2010,107-117.

[9]. AJ Berger,K Alford, Cardiac arrest in a young man following excess consumption of caffeinated 'energy drinks'. Med J Aust ,190,2009,41-43.

[10]. N Gunja, JA Brown. Energy drinks: health risks and toxicity. Med J Aust 2012;196,2012,46-49.

[11]. K Babu,R Church,W Lewander, Energy drinks: the new eye opener for adolescents. Clin Pediat Emerg Med 9,2008,35-42.

[12]. E Fayle and J.A. Gerrard,The Maillard Reaction. Royal society of Chemistry, Cambridge.2002.

[13]. M A J S van Boekel ,Effect of heating on Maillard reactions in milk., Food Chem. ,62,1998,403-414

[14]. J.E. Hodge, Chemistry of browning reactions in model systems. Journal of Agric. Food Chem. 1,1953,928-943.

[15]. H Nursten, The Maillard Reaction. Chemistry, Biochemistry and Implication. The Royal society of Chemistry. Cambridge. 2005.

[16]. H R Glatt and Y Sommer, Health risks by 5-hydroxymethylfurfural (HMF) and related compounds. K. Skog, J. Alexander (Eds.), Acrylamide and other health hazardous compounds in heat-treated foods. Woodhead Publishing, Cambridge.2006. 328-357.

[17]. C Edoardo and F Vincenzo, Acrylamide and 5-hydroxymethylfurfural (HMF): A review on metabolism, toxicity, occurrence in food and mitigation strategies. Journal of LWT-Food Science and Technology. 44(4),2011,793-810.

[18]. L.J.Durling, L Busk, L and B E Hellman, Evaluation of the DNA damaging effect of the heat-induced food toxicant 5hydroxymethylfurfural (HMF) in various cell lines with different activities of sulfotransferases. Food Chem. Toxicol.,47 (4),2009, $880-884$. 
[19]. S Windson, K Kavazos and P Brooks, The quantitation of hydroxymethylfurfural in Australian Leptospermum honeys. Journal of Pharmacognosy and Phytotherapy. 5 ,2012,21-25.

[20]. N Singh and PK Bath, Quality evaluation of different types of Indian honey. Food Chem., 58: 1-2, 1997,129-133.

[21]. V Gokmen and J Acar, Simultaneous determination of 5-hydroxymethylfurfural and patulin in apple juice by reversed-phase liquid chromatography. Journal of Chromato.A. 847,1999, 69-74.

[22]. D Blanco Gomis ,M.D.Gutierrez,L Sopena Naredo and J.J. Mangas Alonso, High Performance Liquid Chromatographic determination of furfural and hydroxymethylfurfural in apple juices and concentrates. Chromatographia, 32,,1991,45-48.

[23]. V Gokmen and J Acar, Simultaneous determination of 5-hydroxymethylfurfural and patulin in apple juice by reversed-phase liquid chromatography. Journal of Chromatography A. 847,1999, 69-74.

[24]. Bravo, Adriana; Julio C. Herrera, Erika Scherer, Yon Ju-Nam, Heinrich Rübsam, Jorge Madrid, Carsten Zufall and Rafael RangelAldao (2008). Formation of $\alpha$-dicarbonyl compounds in beer during storage of Pilsner. Journal of Agricultural and Food Chemistry $56(11), 2008,4134-4144$.

[25]. C Delgado-Andrade, I Seiquer, M P Navarro and FJ Morales, Estimation of hydroxymethylfurfural availablility in breakfast cereals. Studies in Caco-2 cells. Food Chem. Toxicol, 46 (5),2008,1600-1607.

[26]. J.A.R.Henares, Analysis of heat-damage indices in breakfast cereals :Influence of composition. Journal of Cereal Science. 43:,2006,63-69.

[27]. Antonio Ramirez-Jimenez,Belen Garcia-Villanova and Eduardo Guerra-Hernandez,Hydroxymethyl furfural and methylfurfural content of selected bakery products. Food. Res.Int.,33,2000,833-838.

[28]. M.Mukovic and MA Bornik, Formation of 5-hydroxymethyl-2-furfural (HMF) and 5-hydroxymethyl-2-furoic acid during roasting of coffee.Mol Nutr Food Res. 51(45),2007,390-394.

[29]. M.Mukovic andN.Pichler, Analysis of 5-hydroxymethylfurfual in coffee, dried fruits and urine. Molecular Nutrition \& Food Research ,50(9),2006,842-846.

[30]. I Birlouez-Aragon,M Nicolas, A Metais, N Marchond, J Grenier and D Calvo,A rapid fluorimetric method to estimate the heat treatment of liquid milk. International Dairy Journal, 8, 1998,771-777.

[31]. AOAC.Official methods of analysis(method925.10)(15 th ed).Arlingtin VA, Association of Official Analytical Chemists, 1990

[32]. A Shrivastava and V B Gupta, Methods for the determination of limit of detection and limit of quantitation of the analytical methods. Chron Young Sci [serial online] [cited 2013 Sep 17];2:21-5. Available from: http://www.cysonline.org/text.asp?2011/2/1/21/ 79345 .

[33]. S Windson, K Kavazos and P Brooks,(2012). The quantitation of hydroxymethylfurfural in Australian Leptospermum honeys. Journal of Pharmacognosy and Phytotherapy. 5 ,2012, 21-25. 